\title{
Effects of topical capsaicin in seasonal allergic rhinitis
}

\author{
Lennart Greiff, Christer Svensson, Morgan Andersson, Carl G A Persson
}

Department of Otorhinolaryngology

L Greiff

C Svensson

$M$ Andersson

Department of Clinical Pharmacology C G A Persson

Lund University Hospital, S-22185 Lund, Sweden

Reprint requests to: Dr L Greiff.

Received 17 January 1994 Returned to authors 18 July 1994

Revised version received 26 August 1994 Accepted for publication 26 September 1994

\begin{abstract}
Background - Mucosal exudation (luminal entry) of bulk plasma is a key feature of airway defence and inflammation. In guinea pig and rat airways this response is readily produced by neurogenic irritants, notably capsaicin. Thus "neurogenic airway inflammation" has become an established concept. The present study examines whether capsaicin also produces mucosal exudation of plasma in human nasal airways both in health and disease (seasonal allergic rhinitis).

Methods - Pain-producing concentrations of capsaicin $(30-300 \mathrm{ng} / \mathrm{ml})$ were applied to the nasal mucosal surface both before and late into the pollen season. Levels of albumin in nasal lavage fluid were measured as an index of mucosal exudation of plasma. In a separate group of patients with seasonal allergic rhinitis nasal challenge with an exudative concentration of histamine was carried out before the birch pollen season and concentrations of albumin in lavage fluid were measured.

Results - Pollen counts and symptom scores revealed a mild pollen season. Capsaicin produced considerable nasal pain and this response was augmented late into the season when capsaicin also produced nasal blockage. However, capsaicin failed to produce any mucosal exudation of plasma either before or late into the pollen season. The exudative effect of histamine was confirmed.

Conclusions - The augmented pain response to capsaicin suggests that a sensory nerve hyperresponsiveness may characterise allergic airways disease. In contrast to the effects on animal airways, capsaicin failed to produce mucosal exudation of plasma in the human nasal airway. The animal based neurogenic inflammation concept is therefore not valid for the human nasal airway, not even in inflamed airways when a neural hyperresponsiveness has developed.

(Thorax 1995;50:225-229)
\end{abstract}

Keywords: allergy, rhinitis, neurogenic inflammation, capsaicin.
Luminal entry or mucosal exudation of bulk plasma is a key feature of airway inflammation ${ }^{1}$ and plasma exudation has been seen in allergic and infectious airway diseases. ${ }^{2-4} \mathrm{Nasal}$ and bronchial airways appear to respond equally to exudative challenges. ${ }^{1}$ The epithelial lining, even when intact, allows rapid entry of plasma into the airway lumen through valve-like paracellular pathways. ${ }^{1}$ Plasma proteins in airway mucosal surface liquids may thus directly reflect the intensity of the subepithelial inflammation. ${ }^{1}$

In rat and guinea pig airways mucosal exudation of plasma is readily induced by irritants such as capsaicin ${ }^{5}$ and nicotine. ${ }^{6}$ It has been shown that irritants release neural tachykinins which increase airway microvascular permeability in these animals. ${ }^{7-9}$ Kröll et al ${ }^{10}$ have further shown that the release in guinea pig airways and lung may be through a local axon reflex.

Based largely on these animal observations it has been suggested that neurogenic inflammation may be a feature of human airway disease. Capsaicin has been shown to produce pain and atropine-dependent rhinorrhoea in the human nasal airway, ${ }^{11}$ and its major effect in the lower airways appears to be cough. ${ }^{12}$ No observations have been made so far to indicate that irritants can produce airway inflammation and mucosal exudation of plasma in human airways.

The human nose may be used for studies of inflammation that are also relevant to the lower airways. ${ }^{1}$ In a study in healthy subjects we have shown that nasal challenge with nicotine produces intense nasal pain and dose-dependent secretion of mucin, but fails to produce any mucosal exudation of plasma. ${ }^{13}$ Similarly, in healthy subjects Bascom et $a l^{14}$ found no mucosal exudation of albumin in nasal airways challenged with capsaicin. Ignoring the fact that luminal entry of plasma reflects the permeability of the subepithelial microcirculation, these authors did not emphasise that their observations could question the relevance of neurogenic inflammation in humans. ${ }^{14}$ Neither capsaicin nor nicotine has been evaluated in human airways when inflammation is already present.

In the present study we have examined 
whether capsaicin, given topically in doses that can be tolerated acutely, induces mucosal exudation of plasma in patients with seasonal allergic rhinitis. Capsaicin challenges were performed before and late into the birch pollen season and concentrations of albumin in the lavage fluid and any induced nasal symptoms including pain were determined. To compare the effects of capsaicin with those of an exudative inflammatory mediator a histamine challenge test was performed before the birch pollen season in a separate group of patients with seasonal allergic rhinitis using an exudative concentration of histamine in the middle part of the concentration-response curve. ${ }^{15}$

\begin{abstract}
Methods
SUBJECTS

Eleven patients (eight men) with seasonal allergic rhinitis aged 22-28 years received capsaicin challenge before and late into the birch pollen season. A separate group of 10 patients (nine men) with allergic rhinitis aged 19-47 years received histamine challenge outside the birch pollen season. All patients had a history of strictly seasonal allergic rhinitis and a positive skin prick test to birch pollen allergen. No drugs were allowed during and for one month before the study. The study was approved by the local ethics committee and informed consent was obtained.
\end{abstract}

\section{POLLEN COUNT AND SYMPTOM SCORE}

The daily birch pollen count was registered using a pollen trap located in the study region. The pollen count was expressed as mean daily number of pollen grains $/ \mathrm{m}^{3}$ of air. Overall nasal symptoms - that is, sneezes, blockage, and rhinorrhoea - were scored by the patients once daily using a symptom score where $0=$ no symptoms, $1=$ mild, $2=$ moderate, and $3=$ severe. After capsaicin challenge nasal blockage and nasal pain were scored as $0=$ none, $1=$ mild, $2=$ moderate, and $3=$ severe, and sneezes as $0=0$ sneezes, $1=1-4$ sneezes, $2=5-9$ sneezes, and $3=\geqslant 10$ sneezes. No attempt was made to estimate secretion after capsaicin challenge because of difficulties in distinguishing between lavage fluids and actual rhinorrhoea. Capsaicin challenges were carried out before the birch pollen season (early in March) and late into the pollen season (study day 30, see fig 1). Study day 1 was 15 April 1992.

\section{NASAL POOL TECHNIQUE}

A nasal pool device was used for concomitant capsaicin challenge and lavage of the nasal mucosa $a^{15}$ and for histamine challenge and lavage in the separate group of patients with seasonal allergic rhinitis. The nasal pool device is a compressible plastic container equipped with a nasal adapter. The adapter is inserted into one of the nostrils and the container is compressed by the sitting subject leaning forward in a $60^{\circ}$ flexed neck position. The nasal pool fluid is then instilled into one of the nasal cavities and maintained in contact with a large and defined area of the mucosal surface for an extended period of time. When the pressure on the device is released the fluid returns into the container. In the present study the volume of the nasal pool fluid was $14 \mathrm{ml}$.

\section{NASAL CHALLENGES AND LAVAGES}

Isotonic saline and capsaicin (30 and $300 \mathrm{ng} /$ $\mathrm{ml}$ ) dissolved in isotonic saline were introduced in sequence into the nasal cavity using the nasal pool technique. The fluid was maintained in the nasal cavity for 10 minutes and two minutes elapsed between each instillation. Before each 10 minute instillation the mucosal surface was irrigated by two 30 second saline lavages to remove albumin that might have accumulated on the mucosal surface. Furthermore, to prevent capsaicin from being retained in the nasal airway the mucosal surface was irrigated by a 30 second saline lavage using the nasal pool technique, immediately after each 10 minute challenge. (These brief lavages were not collected.) In the separate group of patients with allergic rhinitis isotonic saline and histamine $(400 \mu \mathrm{g} / \mathrm{ml})$ in isotonic saline were each introduced into the nasal cavity for 10 minutes using the nasal pool technique. Two minutes elapsed between the instillations and the mucosal surface was irrigated by two 30 second saline lavages before each 10 minute instillation. The recovered fluids were centrifuged $\left(105 \mathrm{~g}, 10\right.$ minutes, $\left.4^{\circ} \mathrm{C}\right)$ and samples were obtained from the supernatant and frozen $\left(-20^{\circ} \mathrm{C}\right)$ awaiting analysis.

\section{ALBUMIN ANALYSIS}

The concentrations of albumin in the lavage fluid were measured using a radioimmunoassay sensitive to $6 \cdot 25 \mathrm{ng} / \mathrm{ml}$. Rabbit anti-human albumin (Dakopatts, Copenhagen, Denmark) and standard (Calbiochem, San Diego, California, USA) were used. Iodination was performed by the lactoperoxidase method to a specific activity of $2.0 \mathrm{mCi} / \mathrm{nmol} .^{16}$ Tracer and standard or sample were mixed with antiserum before adding goat anti-rabbit antiserum (Astra Draco, Lund, Sweden). The bound fraction was measured by a gamma camera (Pharmacia, Uppsala, Sweden). The intraassay and interassay coefficients of variation were $5 \%$ and $10 \%$, respectively.

\section{DATA ANALYSIS}

The Friedman test and Wilcoxon signed rank test were used to examine differences in pollen counts and overall nasal symptoms during the pollen season, and to examine differences in symptoms and lavage fluid levels of albumin in capsaicin challenged subjects before and late into the pollen season, respectively. The Wilcoxon signed rank test was used to examine differences in lavage fluid levels of albumin between patients challenged with isotonic saline and histamine before the pollen season. p values $<0.05$ were considered significant. Data are presented as means (SE). 


\section{Results}

The pollen counts and symptom scores registered during the birch pollen season revealed a mild but significant pollen season (fig 1). The nasal symptom scores were significantly increased on study days 15 and $19-35(\mathrm{p}<0.05-$ 0.001 ) compared with study day 1 (fig $1 \mathrm{~B}$ ).

Capsaicin challenges produced dose-dependent nasal pain (burning sensation) both before and late into the birch pollen season (Friedman test, $\mathrm{p}<0.001$ ) (fig 2 ). This response was significant for capsaicin $300 \mathrm{ng} / \mathrm{ml}$ (Wilcoxon signed rank test, $\mathrm{p}<0 \cdot 01$ ) compared with the saline control. Late into the birch pollen season the pain response to capsaicin $300 \mathrm{ng} /$ $\mathrm{ml}$ was significantly greater than before the season (Wilcoxon signed rank test, p<0.05). Capsaicin failed to produce significant sneezes either before or late into the pollen season, but produced significant nasal blockage late into the season (Friedman test, $\mathrm{p}<0.01$; Wilcoxon signed rank test, $\mathrm{p}<0.05$, comparison between control saline and capsaicin $300 \mathrm{ng} / \mathrm{ml}$ ) (fig 2).

Capsaicin challenges failed to produce mucosal exudation of albumin either before or late into the birch pollen season (fig 3). Indeed, repeated administrations of increasing concentrations of capsaicin produced successively smaller levels of albumin in the lavage fluid.
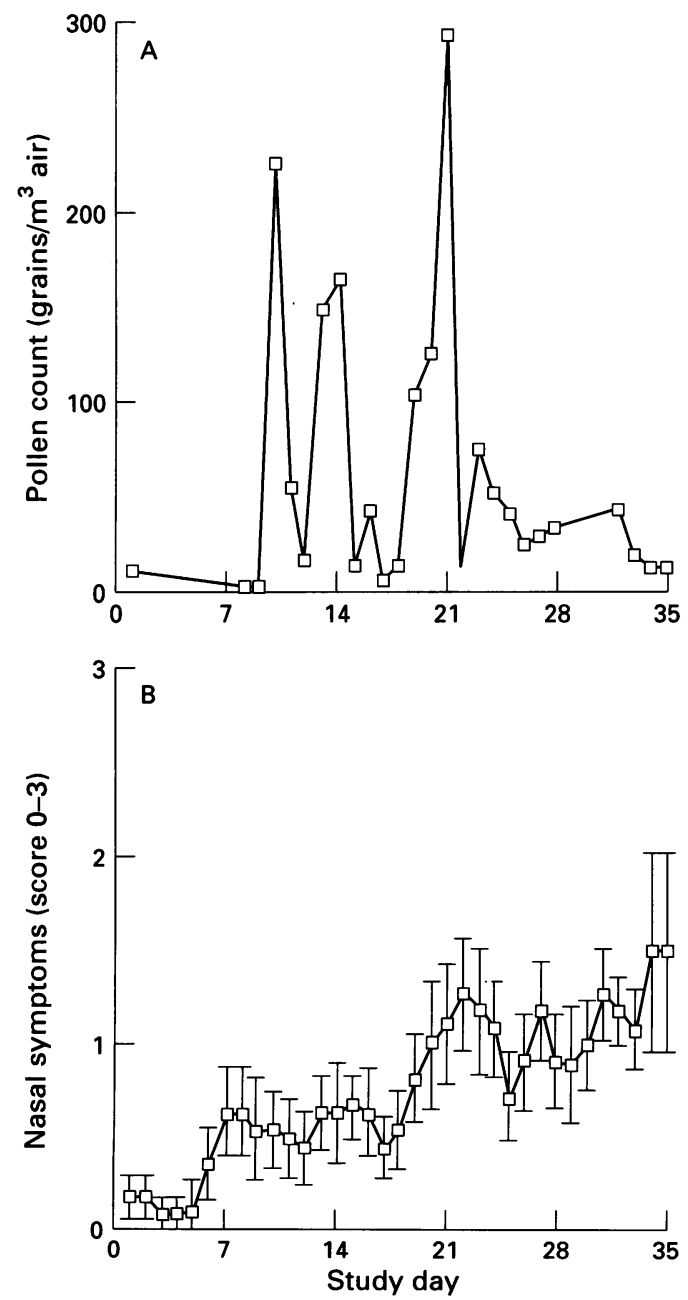

Figure 1 (A) Daily pollen counts and (B) nasal symptom scores revealed a mild but significant birch pollen season. Capsaicin challenges were performed before the start of the season (early in March) and late into the season (study day 30). Study day 1 is 15 April 1992.
This effect of the repeated lavages was significant late into the season (Friedman test, $\mathrm{p}<0.01$; Wilcoxon signed rank test, $\mathrm{p}<0.05$ isotonic saline versus capsaicin $30 \mathrm{ng} / \mathrm{ml}$, $\mathrm{p}<0.01$ isotonic saline versus capsaicin $300 \mathrm{ng} /$ $\mathrm{ml}$ ). In contrast, the histamine challenge carried out in the separate group of patients with seasonal allergic rhinitis produced considerable mucosal exudation of albumin $(p<0.01)$ (fig 3$)$.

\section{Discussion}

In this study we have examined patients with seasonal allergic rhinitis both before and late into a mild but significant birch pollen season. We have previously shown increased levels of plasma proteins in nasal lavage fluid in mild seasonal allergic rhinitis. ${ }^{4}$ Furthermore, we have shown that the airway microcirculation is hyperresponsive to exudative mediator challenge late into the pollen season. ${ }^{17}$ Hence, the presence of allergic disease may offer particular opportunities to detect plasma exudation responses. Repeated lavages with isotonic saline were carried out before the cap-
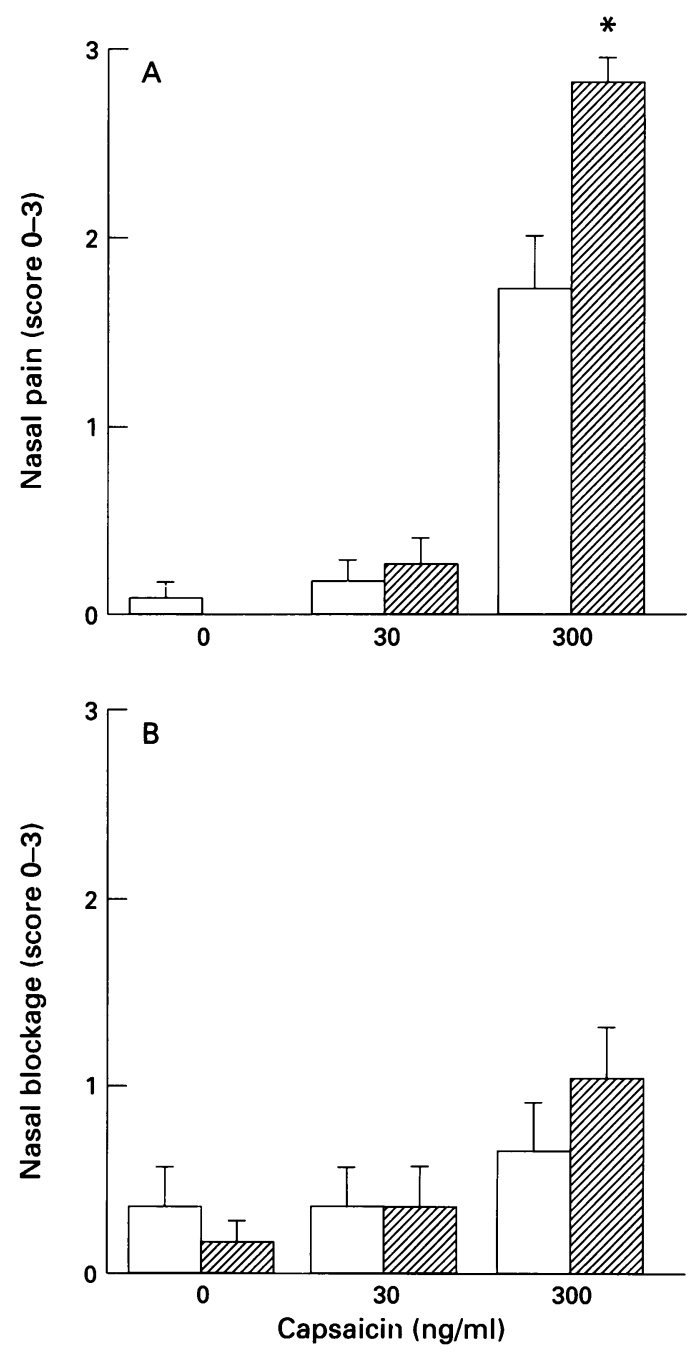

Figure 2 (A) Capsaicin produced nasal pain (burning sensation) both before (open columns) and late into (filled columns) the birch pollen season. This effect was increased late in the season $\left(^{*}<<0.05\right)$. (B) Capsaicin produced significant nasal blockage late into (filled columns) but not before (open columns) the birch pollen season. There were no significant differences between the capsaicin-induced nasal blockage before and late into the season. 

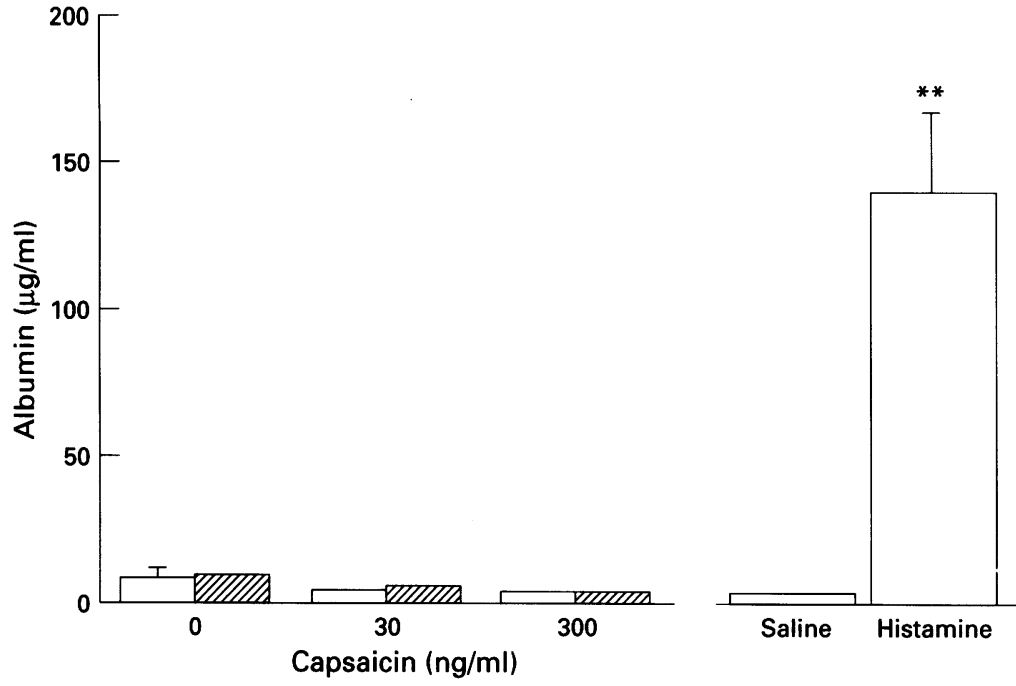

Figure 3 Effects of capsaicin on lavage fluid levels of albumin before (open columns) and late into (filled columns) the birch pollen season, and effects of histamine in a separate group of patients out of the season. Capsaicin failed to produce mucosal exudation of albumin both before and late into the birch pollen season. In contrast, the effect of histamine on plasma exudation was confirmed $(* * p<0 \cdot 01)$.

saicin challenge series to remove plasma that may have accumulated on the mucosal surface, thus further increasing the possibility of detecting any mucosal exudation of plasma.

Our results show that capsaicin, in a concentration that produces intense nasal pain, does not produce mucosal exudation of plasma. This negative outcome is equally clear both before and late into the birch pollen season. The capsaicin-induced pain was significantly greater during the season than before the start of the season. Hence, both in healthy conditions and in inflammation, in the presence of a sensory nerve hyperresponsiveness, capsaicin completely failed to produce any inflammatory exudation of plasma in the human airways. These data add significantly to the previous findings with nicotine ${ }^{13}$ and capsaicin. ${ }^{14}$ Taken together, the findings in the human airway suggest that the animal-based concept of neurogenic inflammation may have no bearing on the human nasal airway.

The airways respond to inflammatory challenges such as histamine and allergen with extravasation of plasma from post-capillary venules of the subepithelial microcirculation. ${ }^{1}$ Non-sieved bulk plasma is thus extravasated into the lamina propria along a hydrostatic pressure gradient. The extravasated plasma moves up between the epithelial cells and may exert a hydrostatic pressure load on the basolateral aspects of the epithelial cells from beneath. ${ }^{1}$ In vitro observations suggest that the pressure load produces a transient separation of the right junctions between the epithelial cells so that paracellular pathways are readily created for the clearance of extravasated plasma into the airway lumen. ${ }^{1819}$ We have shown that the plasma extravasation process of the airways can be monitored by analysing the concentrations of plasma proteins in airway mucosal surface liquids. This luminal index - that is, mucosal exudation of plasma - may directly reflect the intensity of the airway inflammation. ${ }^{1}$ The luminal entry of bulk plasma extends to threshold inflammatory challenges. ${ }^{1}$ This is an important consideration in the present study where surface liquids have been sampled. It is unlikely that capsaicin could have produced extravasation of plasma into the lamina propria without incurring a detectable increase in lavage fluid levels of plasma proteins. The mechanism of the epithelial passage of extravasated plasma thus strengthens the present conclusion that capsaicin may not produce plasma exudation in human airways.

Challenges with histamine type mediators or allergen readily produce 100 -fold increases in exudative indices on the surface of the human nasal mucosa. In guinea pig airways the tachykinins and capsaicin are approximately equally effective to these challenges to produce plasma exudation. ${ }^{2021}$ Large topical doses of substance $\mathbf{P}$ on the human nasal mucosa may produce significant systemic cardiovascular actions but only marginal or small secretory effects. ${ }^{22}{ }^{23} \mathrm{By}$ far the largest effects have been found by Braunstein et al who reported that albumin and total protein increased 4-10 times in nasal lavage fluids obtained after large topical doses of either substance $P$ or neurokinin A had been given. ${ }^{23}$ It is not known to what degree these data represent secretion of albumin. Further studies involving measurement of specific indices such as $\alpha_{2}$-macroglobulin are needed to establish whether or not exogenous tachykinins may produce any plasma exudation responses in human airways. Indeed, so far only guinea pigs and rats have been found to exhibit neurogenic exudative inflammation in the airways. Considering the lack of supportive data from other species including rabbits, cats, dogs, pigs, and monkeys, it is not surprising that the human airways also lack this mechanism, most clearly shown by the absence of capsaicininduced exudative actions. Whether the airways of humans and other species contain nerves that might release tachykinins is another matter for investigation.

It is difficult to examine mechanisms of the plasma exudation response in the human bronchial airways with great accuracy. The concentration and distribution of challenge agents and lavage fluids on the mucosal surface may not be well controlled, and it may be difficult to distinguish between lavages of the airway and the alveolar surface. It is fortunate, therefore, that the upper and lower airways may exhibit similar responses to inflammatory challenges, particularly plasma exudation responses. ${ }^{1}$ We suggest that the present findings in the nasal airways are also valid for the bronchial airways.

Non-specific airway hyperresponsiveness to topical challenges is a feature of rhinitis and asthma. In the present study we have shown that capsaicin-induced pain was significantly greater late in the season than outside the season. This suggests that sustained airway inflammation may be associated with an increased responsiveness of sensory nerves. We have previously shown a microvascular hyperresponsiveness in allergic rhinitis in which histamine produced greater plasma exudation responses late in the season than outside the 
season. ${ }^{17}$ In the nose it has thus been possible to differentiate responses to topical challenges in terms of specific mucosal end organ involvement, and the microcirculation, the sensory nerves, and the secretory glands may therefore become hyperresponsive. In the present study capsaicin produced significant nasal blockage only during the season, which may be interpreted as another expression of hyperresponsiveness rather than pain. Changes in specific end organ responsiveness may characterise different airway diseases and add information that cannot be obtained by studies of non-specific airway responsiveness. The hyperalgesic response in this study may not be explained by increased mucosal penetration of capsaicin because mucosal absorption in patients with ongoing seasonal allergic rhinitis may actually be reduced. ${ }^{24}$

The previous animal data have clearly shown that capsaicin produces inflammatory exudation in healthy airways. We have now shown that this particular response is not evoked in human airways, either in health or in disease. There are, of course, many inflammatory airway conditions in addition to seasonal allergic rhinitis in which the effect of capsaicin could be evaluated. The present observations do not therefore exclude the possibility that neurogenic inflammatory exudation may be evoked in human airways.

The results of this study indicate that capsaicin does not produce mucosal exudation of plasma in the human nasal airway of patients with allergic rhinitis, neither before nor late into a mild birch pollen season. We suggest that the neurogenic inflammatory responses which are readily produced by capsaicin in guinea pig and rat airways have no relevance to human airways.

This study was supported by the Swedish Medical Research Council (Project 8308), the Medical Faculty of Lund University, and the Swedish Association against Asthma and Allergy.

1 Persson CGA, Svensson C, Greiff L, Andersson M, Wollmer $\mathrm{P}$, Alkner U, et al. The use of the nose to study the inflammatory response in the respiratory tract (editorial). Thorax 1992;47:993-1000.

2 Salomonsson P, Grönneberg R, Gilljam H, Andersson $\mathrm{O}$, Billing B, Enander I, et al. Bronchial exudation of bulk plasma at allergen challenge in allergic asthma. Am Rev Respir Dis 1992;146:1535-42.

3 Åkerlund A, Greiff L, Andersson M, Bende M, Alkner U, Persson CGA. Mucosal exudation of fibrinogen in coronavirus-induced common cold. Acta Otolaryngol 1993;113:642-8.

4 Svensson C, Klementsson H, Andersson M, Pipkorn U,
Alkner U, Persson CGA. Glucocorticoid-induced attenuation of mucosal exudation of fibrinogen and bradykinins in seasonal allergic rhinitis. Allergy 1994;49: 177-83.

5 Persson CGA, Erjefält I. Inflammatory leakage of macromolecules from the vascular compartment into the tracheal lumen. Acta Physiol Scand 1986;126:615-6.

6 Greiff L, Erjefält I, Wollmer P, Andersson M, Pipkorn U, Alkner $U$, et al. Nicotine evokes neurogenic mucosal exudation of plasma into guinea pig but not into human airways. In Greiff L. Plasma exudation and solute absorption airways. In Greiff L. Plasma exudation and solute absorption across the air $109-23$.

7 Lundblad L, Saria A, Lundberg JM, Änggård A. Increased vascular permeability in rat nasal mucosa induced by substance $\mathrm{P}$ and stimulation of capsaicin-sensitive trigeminal neurons. Acta Otolaryngol 1983;96:479-84.

8 Saria A, Martling CR, Yan Z, Theodorsson-Norheim E, Gamse R, Lundberg JM. Release of multiple tachykinins from capsaicin sensitive sensory nerves in the lung by bradykinin, histamine, dimethylphenyl piperazinium, and bradykinin, histamine, dimethylphenyl piperazinium, and vagal ne $1330-5$.

9 McDonald DM. Neurogenic inflammation in the trachea I. Changes in venules, leukocytes, and epithelial cells. $\dot{f}$ Neurocytol 1988;17:583-603.

10 Kröll F, Karlsson JA, Lundberg JM, Persson CGA. Capsaicin-induced bronchoconstriction and neuropeptide release in guinea pig perfused lungs. 7 Appl Physiol 1990; 68:1679-87.

11 Stjärne P, Lundblad L, Lundberg JM, Änggård A. Capsaicin and nicotine-sensitive afferent neurones and nasal secretion in healthy human volunteers and in patients with vasomotor rhinitis. Br f Pharmacol 1989;96:693-701.

12 Midgren B, Hansson L, Karlsson J-A, Simonsson BG, Persson CGA. Capsaicin-induced cough in man. Am Rev Respir Dis 1992;146:347-51.

13 Greiff L, Wollmer P, Erjefält I, Andersson M, Pipkorn U, Persson CGA. Effects of nicotine on the human nasal mucosa. Thorax 1993;48:651-5.

14 Bascom R, Kagey-Sobotka A, Proud D. Effect of intranasal capsaicin on symptoms and mediator release. $\mathcal{F}$ Pharmacol Exp Ther 1991;259:1323-7.

15 Greiff L, Alkner U, Pipkorn U, Persson CGA. The "nasal pool-device" applies controlled concentrations of solutes on human nasal airway mucosa and samples its surface exudations/secretions. Clin Exp Allergy 1990;20:253-9.

16 Thorell JI, Johansson BG. Enzymatic iodination of polypeptides to high-activity. Biochim Biophys Acta 1971;251: 363-9.

17 Persson CGA, Greiff L, Svensson C, Andersson M, Åkerlund A, Wollmer $\mathrm{P}$, et al. Exudative hyperresponsiveness of the airway microcirculation in allergic rhinitis and common cold (abstract). Am Rev Respir Dis 1993;147:A833.

18 Gustafsson B, Persson CGA. Asymmetrical effects of in creases in hydrostatic pressure on macromolecular movement across the airway mucosa. Clin Exp Allergy 1991;21: 121-6.

19 Persson CGA, Erjefält I, Gustafsson B, Luts A. Subepithelial hydrostatic pressure may regulate plasma exudation across the mucosa. Int Arch Allergy Appl Immunol 1990;92:14853.

20 Persson CGA, Erjefält I, Andersson P. Leakage of macromolecules from guinea-pig tracheobronchial microcirculation. Effects of allergen, leukotrienes, tachykinins, and anti-asthma drugs. Acta Physiol Scand 1986;127:95105.

21 Erjefält I, Persson CGA. Inflammatory passage of plasma macromolecules into airway wall and lumen. Pulm Pharmacol 1989;2:93-102.

22 Malm L, Petersson G. Tachykinins and nasal secretion. In: Håkansson R, Sundler F, eds. Tachykinin antagonists. Amsterdam: Elsevier Biomedical 1995: 199-202.

23 Braunstein G, Fajac I, Lacronique J, Frossarsd N. Clinical and inflammatory responses to exogenous tachykinins in allergic rhinitis. Am Rev Respir Dis 1991;144:630-5.

24 Greiff L, Wollmer P, Svensson C, Andersson M, Persson CGA. Effects of seasonal allergic rhinitis on airway mucosal absorption of chromium-51 labelled EDTA. Thorax 1993;48:648-50. 